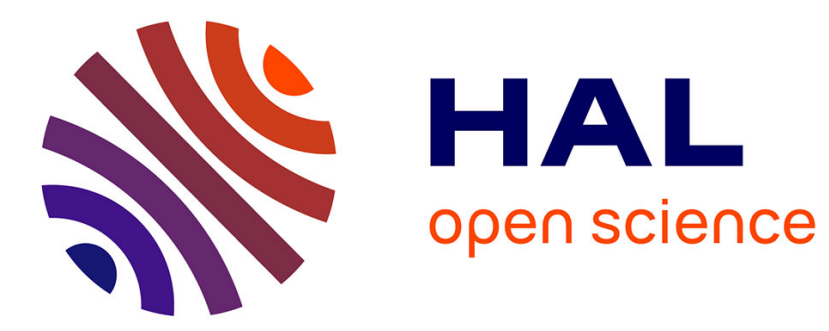

\title{
Contrasting Regional Soil Alteration Across the Topographic Dichotomy of Mars
}

D. Hood, S. Karunatillake, O. Gasnault, A. Williams, B. Dutrow, L. Ojha, S. Kobs, K. Kim, J. Heldmann, C. Fralick

\section{> To cite this version:}

D. Hood, S. Karunatillake, O. Gasnault, A. Williams, B. Dutrow, et al.. Contrasting Regional Soil Alteration Across the Topographic Dichotomy of Mars. Geophysical Research Letters, 2019, 10.1029/2019GL084483 . hal-02411482

\section{HAL Id: hal-02411482 \\ https://hal.science/hal-02411482}

Submitted on 1 Dec 2021

HAL is a multi-disciplinary open access archive for the deposit and dissemination of scientific research documents, whether they are published or not. The documents may come from teaching and research institutions in France or abroad, or from public or private research centers.
L'archive ouverte pluridisciplinaire HAL, est destinée au dépôt et à la diffusion de documents scientifiques de niveau recherche, publiés ou non, émanant des établissements d'enseignement et de recherche français ou étrangers, des laboratoires publics ou privés.

$$
\text { Copyright }
$$




\section{Geophysical Research Letters}

\author{
RESEARCH LETTER \\ 10.1029/2019GL084483 \\ Key Points: \\ - Study represents first multivariate \\ analysis of global martian soil \\ chemistry \\ - Chemical trends suggest widespread \\ aqueous interaction with soil in the \\ southern highlands and less \\ interaction in, or transport of altered \\ soils to, the northern lowlands \\ - Findings give evidence for \\ potentially widespread altered soils \\ in southern highlands
}

Supporting Information:

- Supporting Information S1

- Table S1

- Table S2

- Table S3

- Figure S1

- Figure S2

- Figure S3

- Figure S4

- Figure S5

- Figure S6

- Figure S7

- Figure S8

- Figure S9

- Data Set S1

Correspondence to:

D. R. Hood,

dhood7@lsu.edu

Citation:

Hood, D. R., Karunatillake, S. Gasnault, O., Williams, A. J., Dutrow, B., Ojha, L., et al (2019). Contrasting regional soil alteration across the topographic dichotomy of Mars. Geophysical Research Letters, 46 , 13,668-13,677. https://doi.org/10.1029/ 2019GL084483

Received 9 JUL 2019 Accepted 15 NOV 2019

Accepted article online 26 NOV 2019

Published online 3 DEC 2019

C2019. American Geophysical Union. All Rights Reserved.

\section{Contrasting Regional Soil Alteration Across the Topographic Dichotomy of Mars}

\author{
D. R. Hood ${ }^{1}$ iD, S. Karunatillake ${ }^{1}$ iD, O. Gasnault ${ }^{2}$ iD, A. J. Williams ${ }^{3}$ iD, B. Dutrow ${ }^{1}$, L. Ojha ${ }^{4}$ iD, \\ S. Kobs ${ }^{5}$, K. Kim ${ }^{6}$, J. Heldmann ${ }^{7}$, and C. Fralick ${ }^{8}$ \\ ${ }^{1}$ Department of Geology and Geophysics, Louisiana State University, Baton Rouge, LA, USA, ${ }^{2}$ Institut de Recherche en \\ Astrophysique et Planetologie, Toulouse, France, ${ }^{3}$ Department of Geological Sciences, University of Florida, Gainesville, \\ FL, USA, ${ }^{4}$ Department of Earth and Planetary Sciences, Rutgers, The State University of New Jersey, Piscataway, NJ, USA, \\ ${ }^{5}$ Department of Geosciences, Idaho State University, Pocatello, ID, USA, ${ }^{6}$ Korea Institute of Geosciences and Mineral \\ Resources, Daejeon, South Korea, ${ }^{7}$ NASA Ames Research Center, Moffett Field, CA, USA, ${ }^{8}$ Unaffiliated
}

\begin{abstract}
Landscapes on either side of the martian topographic dichotomy bear distinct soil chemistry, but the processes associated with this distinction remain poorly understood. Here, correlation of soil chemistry at global to regional scales is examined with multivariate analysis of Gamma-Ray Spectrometer chemical maps and the Thermal Emission Spectrometer-derived Dust Cover Index (DCI). In the analysis, the northern lowlands show a strong S-Cl correlation, contrasting with the southern highlands, which show a stronger $\mathrm{S}-\mathrm{H}_{2} \mathrm{O}$ correlation. These observations suggest aqueous interaction with soils throughout the southern highlands, preferentially dissolving $\mathrm{Cl}$ compounds and weakening S-Cl correlation. Strong S-Cl correlations in the northern lowlands suggest less interaction with aqueous $\mathrm{H}_{2} \mathrm{O}$. Additionally, regional analyses demonstrate that DCI does not correlate with volatile chemistry at smaller scales and that Ca may be an important component of volatile-bearing material. These results provide new evidence for widespread aqueous interaction and possibly alteration of soil in the southern highlands.
\end{abstract}

Plain Language Summary Mars can be divided into two large regions: the northern lowlands and southern highlands, separated by a planet-circling change in elevation known as the topographic dichotomy. The soils that cover the landscape in these two areas appear distinct from one another, although it is unclear what processes cause this distinction. This investigation examines the chemistry of soils on either side of the dichotomy based on Gamma-Ray Spectrometer data, to elucidate changes in soils. The identified changes in correlation of three soil components, sulfur, chlorine, and $\mathrm{H}_{2} \mathrm{O}$, suggest that much of the southern highlands soils have interacted with water, but fluid interaction occurred far less in the northern lowlands. These findings show that the processes by which water interacts with soils were likely active over larger areas in the southern highlands than previously realized, but such processes were not active after the northern lowlands soils were deposited.

\section{Introduction}

The martian topographic dichotomy is one of Mars' oldest features (e.g., Andrews-Hanna et al., 2008) and separates the northern lowlands from the southern highlands. While the dichotomy is likely early Noachian in age (Frey et al., 2002), the surface ages of these two areas are distinctly different due to a large amount of Hesperian-age material in the northern lowlands (Tanaka et al., 2014). Global assessments of geochemistry also reveal distinctions in the distribution of $\mathrm{H}_{2} \mathrm{O}$ and $\mathrm{S}$ in the shallow subsurface soils that may associate with the dichotomy boundary (Karunatillake et al., 2014). In situ results show that correlations and trends among volatile elements (e.g., $\mathrm{S}, \mathrm{H}_{2} \mathrm{O}$, and $\mathrm{Cl}$ ) can elucidate the amount of alteration (e.g., Haskin et al., 2005), the mineralogy of altered phases (Dehouck et al., 2014), and former aqueous interaction (i.e., presence and migration of fluids, Haskin et al., 2005). Such trends, identified in situ, are considered in soils using Gamma-Ray Spectrometer (GRS) chemical maps and applied to regional-to-global scale soils to examine potential signals of widespread aqueous interaction and alteration in martian soil. This work explores the hypothesis that regionally distinct aqueous histories may cause the geochemical distinction in volatile chemistry across the dichotomy. Older, more altered soils may occur in the south formed by acidic processes such as hydrothermal leaching, aerosols, and low-pH brine films (Hurowitz \& Fischer, 2014; 
McCollom \& Hynek, 2005) or by more neutral-to-alkaline processes (Hurowitz et al., 2017). In contrast in the northern lowlands, younger, less altered soils may have been derived primarily from physical reworking of underlying material with limited fluid interaction.

Aqueous interaction can be evidenced by a variety of indicative minerals (e.g., clays), but remote infrared observations that identify directly these minerals are limited to the optical surface $(<10 \mu \mathrm{m}$ depth $)$ and typically only examine consolidated or lithic material in dust-free areas. These constraints make the Mars Odyssey GRS chemical data key to examining regional- and global-scale trends in soil chemistry. Because GRS generally measures soil chemistry up to $\sim 0.5 \mathrm{~m}$ deep with continuous coverage, it is possible to identify trends in soils at the global scale and evaluate the same soil volatile trends seen at rover and lander sites. Prior work examining the latitudinal variability of the $\mathrm{H}_{2} \mathrm{O}: \mathrm{S}$ ratio in martian bulk soil suggested that sulfate minerals are the primary hydrated phase in the southern highlands and that this may not be the case in the northern lowlands (Karunatillake et al., 2016). However, this work focused solely on $\mathrm{H}_{2} \mathrm{O}$ and S; the influence of $\mathrm{Cl}$ and nonvolatile elements were not considered. In addition, recent work (Ojha et al., 2018) has highlighted dust as a reservoir of $\mathrm{S}$ and $\mathrm{Cl}$ on the martian surface, and specific areas of the surface are suggested to have mantles of sufficient thickness to influence GRS observations (Viviano et al., 2019). The inclusion of $\mathrm{Cl}$, nonvolatile soil chemistry, and a metric for surface dust adds additional dimensions to build upon and advance these previous findings.

Here, principal component analysis (PCA) is applied to the GRS chemical maps and to Thermal Emission Spectrometer-derived Dust Cover Index (DCI) data to identify chemical correlations across the dichotomy that may indicate fluid interaction at hemispheric to global scales. This work is the first global multivariate analysis of the newest set of GRS chemical maps and the first such analysis to incorporate $\mathrm{Ca}, \mathrm{Al}$, and $\mathrm{S}$ maps. This work uses nine chemical maps and DCI to examine chemical changes across the geologically meaningful division: the topographic dichotomy.

\section{Data and Methods}

\subsection{Data Sets}

The primary data set used here is the GRS-derived surface chemistry (referred to as "chemical maps") covering approximately the area from $45^{\circ} \mathrm{N}$ to $50^{\circ} \mathrm{S}$ projected at $5^{\circ} \times 5^{\circ}$ resolution (Figure 1 ). These maps provide chemical abundances for nine elements: the key rock-forming elements $\mathrm{Si}, \mathrm{Ca}, \mathrm{Al}$, and $\mathrm{Fe}$, the incompatible elements $\mathrm{K}$ and $\mathrm{Th}$, and the volatile elements $\mathrm{H}$ (presented as stoichiometrically equivalent $\mathrm{H}_{2} \mathrm{O}$ ), $\mathrm{S}$, and $\mathrm{Cl}$. An important caveat of these maps is that $\mathrm{Mg}$ and $\mathrm{Na}$, important rock-forming elements used in several metrics of soil maturity and alteration (e.g., McCollom \& Hynek, 2005), are not included in chemical maps due to technical limitations (Boynton et al., 2007). Some chemical maps are available at higher resolutions and with improved areal coverage (e.g., $2^{\circ} \mathrm{K}$ and Th maps), but the multivariate analysis is ultimately limited by the coarsest resolution map and by the areas where all nine maps are available (an extent referred to as "midlatitudinal" in this work). Further details on the chemical maps and their derivation can be found in the supporting information section S1.1.

The DCI (Ruff \& Christensen, 2002) is a measure of surface dust abundance derived from Thermal Emission Spectrometer data, specifically the emissivity between 1,350 and $1,400 \mathrm{~cm}^{-1}$ related to the abundance of fine $(<100 \mu \mathrm{m})$ silicate material. DCI is incorporated into analysis to evaluate the correlation between areal coverage of the dust and regional soil chemistry. DCI is available at high lateral resolution (16 pixels per degree) and represents a much shallower depth (tens of microns) compared to the decimeter-scale depth represented by chemical maps. The sampling depth disparity suggests little correlation between DCI and the chemical maps. Nevertheless, DCI was selected over other measures of surface dust (e.g., thermal inertia, Putzig et al., 2005) because it most directly measures the abundance of $<100 \mu \mathrm{m}$ silicate material.

\subsection{Methods}

PCA applies multicomponent chemistry to derive multivariate chemical correlations (e.g., Gasnault et al., 2010) and is applied to the combined chemical maps and DCI data sets at both global and regional scales. In addition to analyzing the entire spatial data set (i.e., midlatitudinal extent), 12 regions (i.e., spatial subsets of the data) were analyzed with the same methods (Figure S1) to capture correlations that are significant at more regional scales. Six regions were selected for either high or low abundance of one of the volatile 


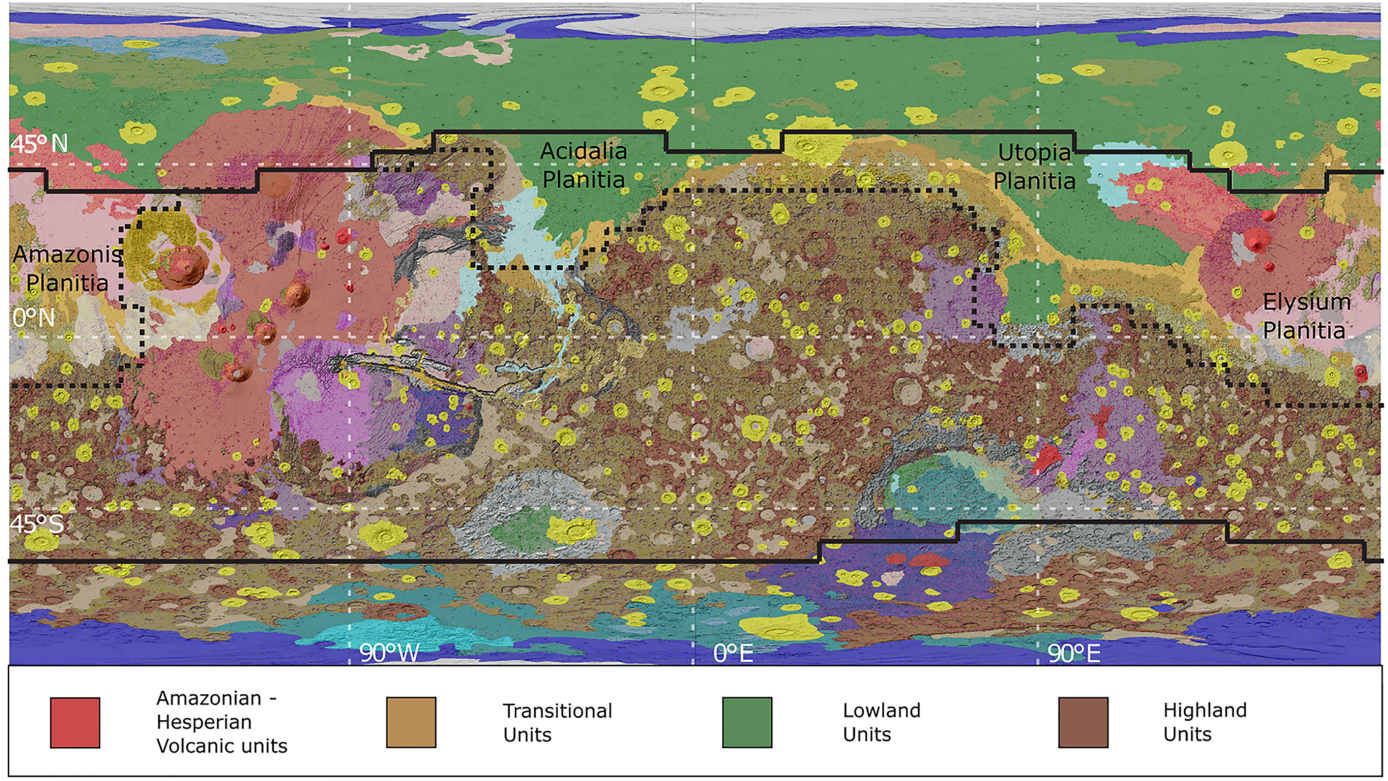

Figure 1. Map of the martian surface showing the extent of the "midlatitudinal" region (solid black lines) for which chemical map data are available overlain on the geologic map of Mars (Tanaka et al., 2014) with several locations labeled. The black dotted line shows the boundary between the northern lowlands and southern highlands regions used in analysis (section 3.1). The simplified legend shows the colors for four of the relevant geologic units: Amazonian and Hesperian volcanism in shades of red, transitional units in shades of gold, lowland units in shades of green, and highland units in shades of brown. Details on the spatial extent of GRS data and the derivation of these regions can be found in the supporting information.

elements $\left(\mathrm{H}_{2} \mathrm{O}, \mathrm{S}\right.$, and $\left.\mathrm{Cl}\right)$ and two for high and low dust cover. These eight regions are intended to isolate the trends that may be prominent only in statistically distinct regions. Two more regions isolating volcanic terrains and nonvolcanic terrains were analyzed to highlight trends potentially driven by lithology. Two regions, the northern lowlands and southern highlands (Tanaka et al., 2014), are isolated to examine trends unique to each region and examine changes across the dichotomy boundary that may indicate distinct soil histories. Results from the northern lowlands region and southern highlands region are discussed in detail as these are the areas of greatest interest (section 3.1), and the remaining 10 regions give context to section 3.1 and provide the broader results in section 3.2. Further details on region selection and coverage can be found in section S1.4.

Most applications to date fail to incorporate uncertainty into PCA, which is addressed here by normalizing GRS and DCI data using both the standard deviation of the data set and the uncertainty of individual values. This method reduces the influence of imprecise data and prevents such data from disproportionately contributing to the variance. The results of this normalization are referred to as " $t$ values" throughout this work, with details in section S1.3. $T$ values also simplify the process of selecting the statistically distinct regions discussed earlier. Each region is defined with a mask, selecting $\geq 2$-pixel contiguous areas that are above +1 or below -1 in $t$ values. This threshold is comparable to 1 standard deviation above or below average at each pixel, with spatial contiguity conferring a statistical confidence in excess of 95\% (Karunatillake et al., 2009).

The primary results of each analysis are the loadings of the principal components, which describe the variations in chemistry and DCI within each region in order of significance. In order to examine inter-regional patterns of correlation, the cosine similarity of vectors in PC space is used as a quantitative measure of correlation in each analysis (Figure 2). The cosine similarity uses the angle between vectors in the projected space as a measure of their similarity or correlation and is commonly used in computer science and information retrieval (Salton \& McGill, 1983). To emphasize the most significant correlations, only the first two principal components (i.e., the directions of primary and secondary variance in the region, typically capturing $50-60 \%$ of the total variance) are used to calculate the cosine similarity. Two related values are used throughout this paper: the cosine similarity, which ranges from 0 to 1 , as the proxy for the correlation coefficient and the cosine similarity angle (CSA), which ranges from $0^{\circ}$ to $180^{\circ}$, to visualize the PCA space (Figure 2). The 

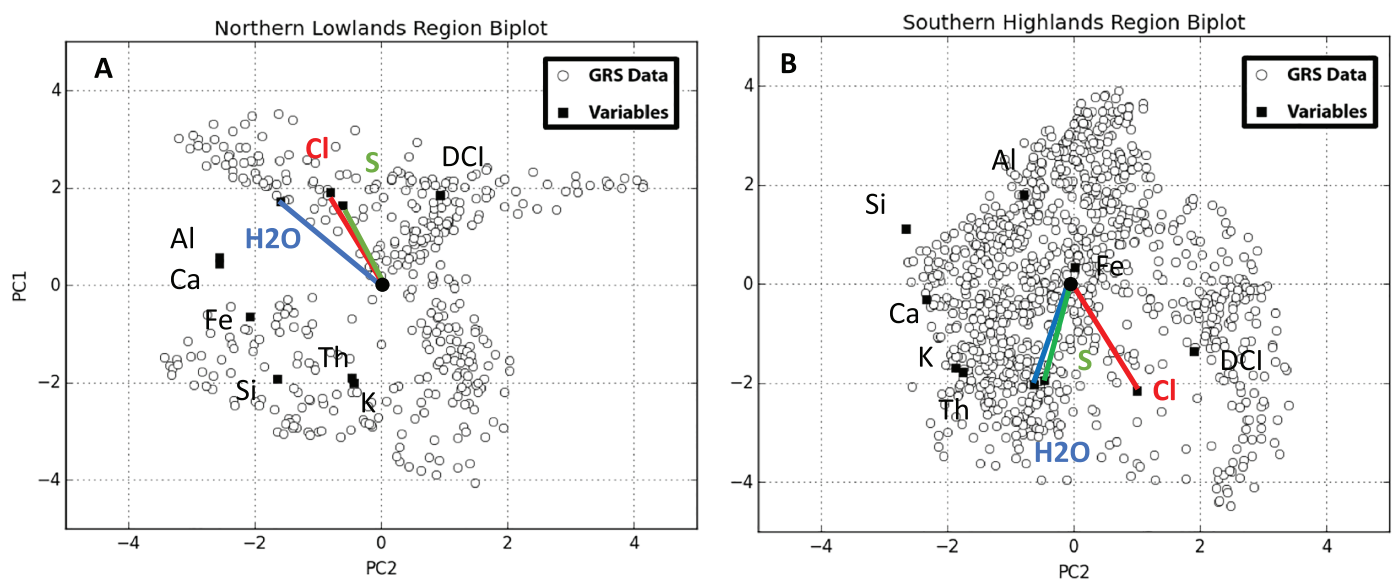

Figure 2. An example of the PC1-PC2 space examined using cosine similarity in both the (a) northern lowlands and (b) southern highlands (sections S1.2 and S1.5 provide details). The white circles show the GRS data set projected into PC1-PC2 space, while the black squares represent the vectors of the original axes (i.e., the loadings of $\mathrm{PC} 1$ and $\mathrm{PC} 2$ for each variable scaled by a common factor for clarity). The vectors for $\mathrm{H}_{2} \mathrm{O}$ (blue), $\mathrm{S}$ (green), and $\mathrm{Cl}$ (red) are marked for clarity These two biplots highlight the distinction between S-Cl- $\mathrm{H}_{2} \mathrm{O}$ trends in the two regions, with $\mathrm{S}$ and $\mathrm{Cl}$ most closely correlated in the northern lowlands, while $\mathrm{S}$ and $\mathrm{H}_{2} \mathrm{O}$ are more closely correlated in the southern highlands.

distribution of CSAs to a reference variable is compiled from the regional analyses in cumulative distribution functions (CDFs; e.g., Figure 3) and examined with two-tailed Kolmogorov-Smirnov (K-S) tests (Massey, 1951). The CDFs show the range of observed CSAs, placing the results from each individual region in context and showing the larger trends in CSAs. The K-S tests show if the distribution of CSAs for each variable is distinct from the distributions for other variables. These tests provide confidence intervals to identify significant mutual correlations that persist at both regional and global scales.

\section{Results}

The analytical methods provide two sets of results: PC loadings that describe the dominant variances within each region and CDFs that describe the global to regional distributions of CSAs for each variable. PC loadings concisely describe the most important variations within each region, providing insight into intra-regional trends in chemistry and DCI. However, detailed discussion of the PC loadings and spatial distributions (as shown in section 3.1) is only warranted in the largest, most cohesive regions. In smaller regions, it is more difficult to attribute meaning to the PC loadings, and the small sample size decreases statistical confidence in findings. For this reason, the CDFs are used for cumulative regional correlation analysis to more confidently describe correlations and trends that occur in multiple regions. Among the 13 PCA results and nine CDFs, the results most relevant to the conclusions are discussed in detail, with more discussion provided in section S2 that supports and reinforces the conclusions.

\subsection{Comparison Between Northern Lowlands and Southern Highlands}

The PCA results for the northern lowlands and southern highlands regions (Figure 2 and Table 1) shed light on the geochemical distinction between the two regions, primarily for $\mathrm{H}_{2} \mathrm{O}, \mathrm{S}$, and $\mathrm{Cl}$ (Figure 2). In the southern highlands, $\mathrm{H}_{2} \mathrm{O}$ and $\mathrm{S}$ are strongly correlated (cosine similarity $=0.998, \mathrm{CSA}=3.9^{\circ}$ ), but $\mathrm{S}$ and $\mathrm{Cl}$ are weakly correlated $\left(0.782,38.5^{\circ}\right.$, Table 1$)$. Comparatively, the northern lowlands show a weaker correlation between $\mathrm{H}_{2} \mathrm{O}$ and $\mathrm{S}\left(0.941,19.7^{\circ}\right)$ and a stronger correlation between $\mathrm{S}$ and $\mathrm{Cl}\left(0.999,2.6^{\circ}\right.$, Table 1). Cumulative results for S (Figure 4) show where these CSAs fall within the distribution of CSAs for all analyses. The $\mathrm{H}_{2} \mathrm{O}-\mathrm{S}$ CSA in the southern highlands is the smallest (i.e., strongest correlation) among the 13 regions, where more than half of the regions have $\mathrm{H}_{2} \mathrm{O}-\mathrm{S}$ CSAs smaller than that seen in the northern lowlands. Similarly, the S-Cl CSA in the northern lowlands is the smallest observed among the 13 regions, and the S-Cl CSA in the highlands is larger than more than half of observed regions. The size of these changes in correlation supports the distinctions as meaningful changes in the correlation of $\mathrm{H}_{2} \mathrm{O}, \mathrm{S}$, and $\mathrm{Cl}$. 


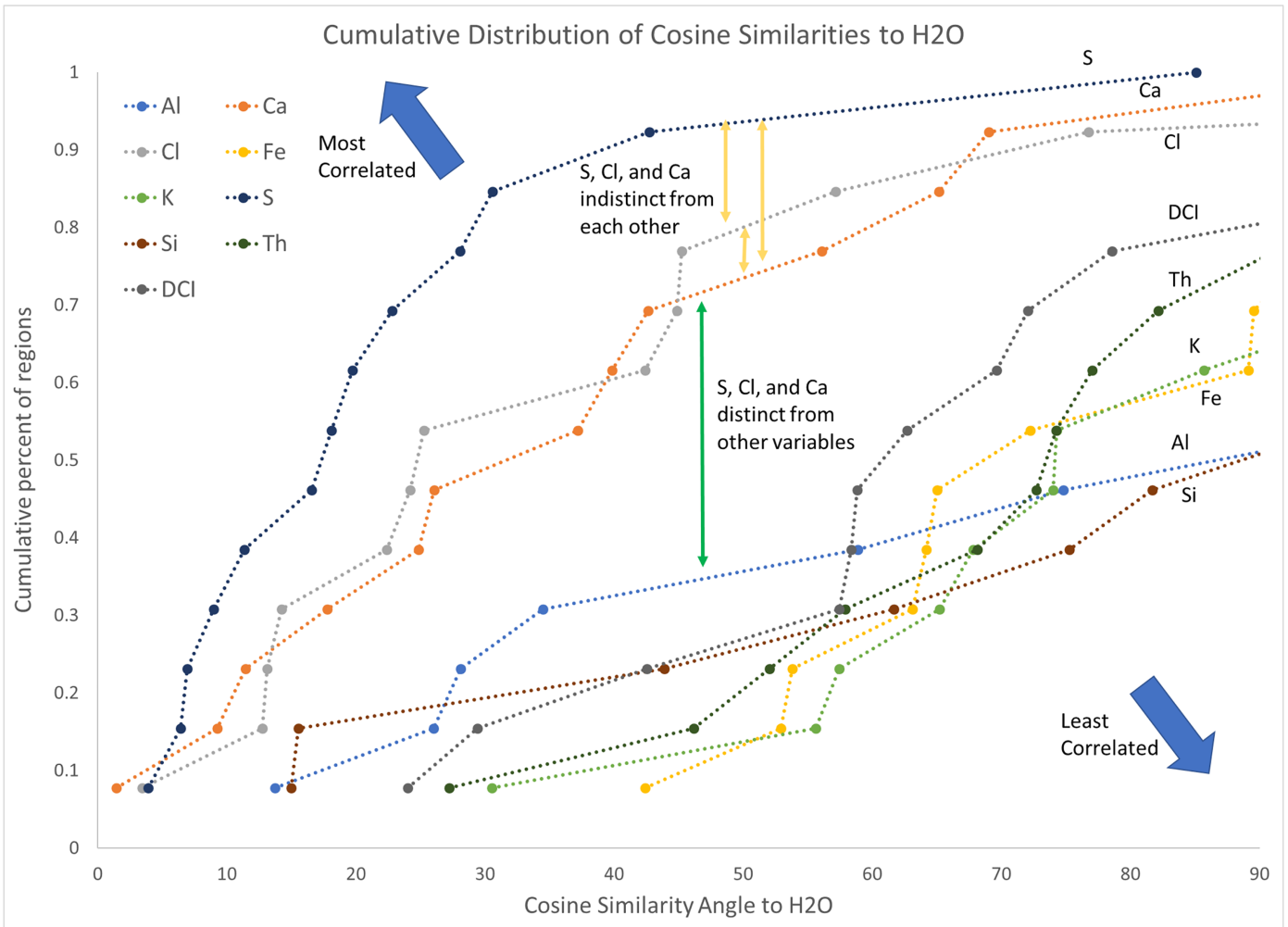

Figure 3. Cumulative PCA results from all regions for $\mathrm{H}_{2} \mathrm{O}$ as the reference variable. The blue arrows generally indicate where variables strongly correlated with $\mathrm{H}_{2} \mathrm{O}$ would plot relative to more weakly correlated variables. The cumulative trend of $\mathrm{S}$, with a large portion of regions at low relative angles, suggests strong spatial correlation relative to the other variables. $\mathrm{Ca}$ and $\mathrm{Cl}$ show similar cumulative trends, indicating weaker correlation with $\mathrm{H}_{2} \mathrm{O}$ than $\mathrm{S}$, but more than the other variables. Important $\mathrm{K}-\mathrm{S}$ results are noted, with yellow lines indicating that the $\mathrm{S}, \mathrm{Cl}$, and $\mathrm{Ca}$ distributions are statistically indistinct from one another and the green line indicating that $\mathrm{S}, \mathrm{Cl}$, and $\mathrm{Ca}$ distributions are statistically distinct from the remaining variables. K-S results are enumerated in Table $\mathrm{S} 3$.

Table 1

PCA Results for Selected Analyses

\begin{tabular}{|c|c|c|c|c|c|c|c|c|c|c|c|}
\hline Region & & $\mathrm{Al}$ & $\mathrm{Ca}$ & $\mathrm{Cl}$ & $\mathrm{Fe}$ & $\mathrm{H}_{2} \mathrm{O}$ & $\mathrm{K}$ & S & $\mathrm{Si}$ & Th & DCI \\
\hline Midlatitudinal & PC1 & 0.318 & -0.087 & -0.478 & -0.128 & -0.448 & -0.199 & -0.443 & 0.156 & -0.238 & -0.360 \\
\hline Var: $51 \%$ & $\mathrm{PC} 2$ & 0.117 & -0.187 & 0.158 & -0.231 & 0.031 & -0.546 & 0.121 & -0.512 & -0.491 & 0.237 \\
\hline \multicolumn{2}{|c|}{ Cosine similarity angle to $\mathrm{H}_{2} \mathrm{O}$} & 155.8 & 69.0 & 14.2 & 65.0 & - & 74.0 & 11.3 & 111.0 & 68.1 & 29.4 \\
\hline \multicolumn{2}{|c|}{ Cosine similarity angle to $\mathrm{S}$} & 144.5 & 80.4 & 2.9 & 76.4 & 11.3 & 85.3 & - & 122.3 & 79.5 & 18.0 \\
\hline Northern lowlands & $\mathrm{PC} 1$ & 0.116 & 0.091 & 0.329 & -0.127 & 0.345 & -0.402 & 0.381 & -0.384 & -0.379 & 0.371 \\
\hline Var: $63 \%$ & $\mathrm{PC} 2$ & -0.512 & -0.513 & -0.122 & -0.417 & -0.320 & -0.086 & -0.162 & -0.327 & -0.093 & 0.188 \\
\hline \multicolumn{2}{|c|}{ Cosine similarity angle to $\mathrm{H}_{2} \mathrm{O}$} & 34.5 & 37.2 & 22.4 & 64.2 & - & 125.2 & 19.7 & 96.7 & 123.5 & 69.6 \\
\hline \multicolumn{2}{|c|}{ Cosine similarity angle to $\mathrm{S}$} & 54.2 & 56.9 & 2.6 & 83.9 & 19.7 & 144.9 & - & 116.5 & 143.2 & 49.9 \\
\hline Southern highlands & $\mathrm{PC} 1$ & 0.361 & -0.062 & -0.430 & 0.066 & -0.403 & -0.338 & -0.387 & 0.224 & -0.356 & -0.269 \\
\hline Var: $53 \%$ & $\mathrm{PC} 2$ & -0.159 & -0.467 & 0.202 & 0.004 & -0.126 & -0.373 & -0.092 & -0.534 & -0.350 & 0.381 \\
\hline \multicolumn{2}{|c|}{ Cosine similarity angle to $\mathrm{H}_{2} \mathrm{O}$} & 138.9 & 65.2 & 42.4 & 166.3 & - & 30.5 & 3.9 & 95.5 & 27.2 & 72.1 \\
\hline \multicolumn{2}{|c|}{ Cosine similarity angle to $\mathrm{S}$} & 142.8 & 69.0 & 38.5 & 170.2 & 3.9 & 34.4 & - & 99.3 & 31.1 & 68.2 \\
\hline
\end{tabular}

Note. The loading values for PC1 and PC2 (i.e., the components of each PC in the original data space) in key analysis including the midlatitudinal, northern lowlands and southern highlands regions (see section 2.2 and Figure 1 for details on regions). \pm 0.316 was used as the cutoff for "significant" associations with a PC (see section S2 for more detail); values outside this range are bolded and highlighted in blue for positive loadings and orange for negative. The variance captured by $\mathrm{PC} 1$ and $\mathrm{PC} 2$ is below each region name. The cosine similarity angle to $\mathrm{H}_{2} \mathrm{O}$ and $\mathrm{S}$ is calculated for each variable in each region, with angles below $25^{\circ}$ highlighted in green. 


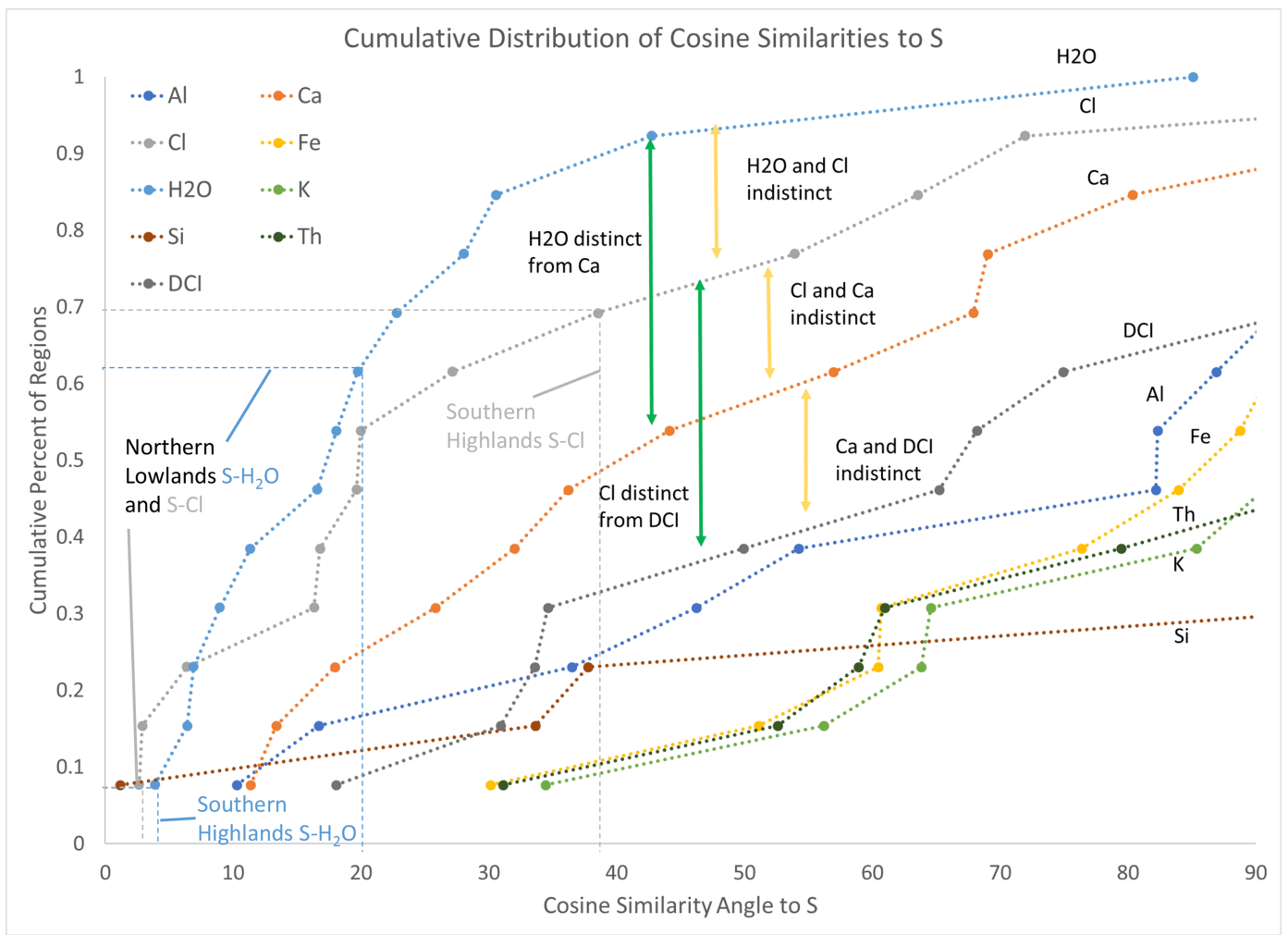

Figure 4. Cumulative PCA results for cosine similarity to $\mathrm{S}$ with the relative angles of $\mathrm{H}_{2} \mathrm{O}$ (blue) and $\mathrm{Cl}$ (gray) to $\mathrm{S}$ of the northern lowlands and southern highlands regions are marked. The northern lowlands show the lowest $\mathrm{S}-\mathrm{Cl}$ angle of any region, while the southern highlands show the lowest $\mathrm{S}-\mathrm{H}_{2} \mathrm{O}$ angle of any region. In contrast, the $\mathrm{S}-\mathrm{H}_{2} \mathrm{O}$ angle in the northern lowlands and $\mathrm{S}-\mathrm{Cl}$ angle in the southern highlands are larger than in a majority of examined regions. Important $\mathrm{K}-\mathrm{S}$ results are marked with green lines indicating mutual distinctness and yellow lines indicating mutual indistinctness. The distribution of $\mathrm{H}_{2} \mathrm{O}$ is distinct from all variables except $\mathrm{Cl}$, and that of $\mathrm{Cl}$ is indistinct from both $\mathrm{H}_{2} \mathrm{O}$ and $\mathrm{Ca}$. Ca is distinct only from $\mathrm{H}_{2} \mathrm{O}$ and the two variables least correlated with $\mathrm{S}$ : $\mathrm{K}$ and $\mathrm{Si}$. Because $\mathrm{H}_{2} \mathrm{O}$ is distinct from $\mathrm{Ca}$ and $\mathrm{Cl}$ is indistinct from $\mathrm{Ca}, \mathrm{H}_{2} \mathrm{O}$ may be more strongly correlated with $\mathrm{S}$ compared to $\mathrm{Cl}$, though only slightly.

\subsection{Cumulative PCA Results}

The cumulative results from all regions for $\mathrm{H}_{2} \mathrm{O}$ (Figure 3) and $\mathrm{S}$ (Figure 4) give context to the result for the northern lowlands and southern highlands and highlight the significance of correlations among the volatile elements $\mathrm{H}_{2} \mathrm{O}, \mathrm{S}$, and $\mathrm{Cl}$ that persist across many regions. The detailed discussion of the cumulative results for DCI is given in section S2.4. In summary, DCI does not show notable correlations with any of the chemical maps, though there is tentative evidence for a correlation with $\mathrm{Cl}$. Cumulative results for the remaining variables ( $\mathrm{Si}, \mathrm{Al}, \mathrm{Fe}, \mathrm{Ca}, \mathrm{K}$, and Th; section S2.4) show generally weak correlations with the other variables. Further discussion of cumulative results is in section S2.4.

The cumulative PCA results and K-S tests for $\mathrm{H}_{2} \mathrm{O}$ (Figure 3 and Table S3) highlight the strong correlations among the volatile elements. CSA distributions of $\mathrm{S}, \mathrm{Ca}$, and $\mathrm{Cl}$ are distinct from the other six variables ( $\mathrm{Si}$, $\mathrm{Al}, \mathrm{Fe}, \mathrm{K}, \mathrm{Th}$, and DCI) and indistinct from one another. This distinction shows that the elements $\mathrm{S}, \mathrm{Cl}$, and $\mathrm{Ca}$ are more significant predictors of $\mathrm{H}_{2} \mathrm{O}$ variance than the other six variables, although relative significance among them cannot be confidently established. The cumulative PCA results for S (Figure 4) and $\mathrm{Cl}$ (Figure S7) reinforce these results: $\mathrm{S}, \mathrm{Cl}$, and $\mathrm{H}_{2} \mathrm{O}$ generally show mutual correlations that are distinct from the remaining variables, and $\mathrm{Ca}$ shows correlation with $\mathrm{S}$ and $\mathrm{H}_{2} \mathrm{O}$ beyond that of the other nonvolatile elements.

The cumulative PCA results and K-S tests for S (Figure 4 and Table S3) generally reinforce the trends seen in the cumulative PCA results for $\mathrm{H}_{2} \mathrm{O}$ (Figure 3). Distributions of CSAs for $\mathrm{H}_{2} \mathrm{O}$ and $\mathrm{Cl}$ are distinct from most of the other variables, notably excepting $\mathrm{Ca}$. However, in this case, a rough hierarchy can be established among $\mathrm{H}_{2} \mathrm{O}, \mathrm{Cl}$, and $\mathrm{Ca}$. The CSA distribution for $\mathrm{H}_{2} \mathrm{O}$ is distinct from all other CSA distributions except 
$\mathrm{Cl}$, the $\mathrm{Cl}$ distribution is indistinct from the $\mathrm{Ca}$ and $\mathrm{H}_{2} \mathrm{O}$ distributions, and $\mathrm{Ca}$ is only distinct from $\mathrm{H}_{2} \mathrm{O}, \mathrm{K}$, and $\mathrm{Si}$. In the context of the other CSA distributions, $\mathrm{H}_{2} \mathrm{O}$ appears to correlate more strongly with $\mathrm{S}$ compared to $\mathrm{Cl}$, and the remaining variables $(\mathrm{K}, \mathrm{Th}, \mathrm{Ca}, \mathrm{Al}, \mathrm{Si}$, and $\mathrm{Fe}$ ) are generally poorly correlated.

\section{Discussion}

\subsection{Aqueous Interaction With Regional Soil Across the Topographic Dichotomy}

The observations in section 3 compound prior bivariate insight into volatile spatial trends (Karunatillake et al., 2016) in three ways: (1) The $\mathrm{S}-\mathrm{H}_{2} \mathrm{O}$ trend is preserved in multivariate space, (2) the change in the $\mathrm{S}-\mathrm{H}_{2} \mathrm{O}$ correlation, previously associated with the hemispheres, persists when comparing each side of the topographic dichotomy, and (3) there is a newly discovered change in the S-Cl correlation associated with the topographic dichotomy. The first two points reinforce existing findings that $\mathrm{S}$ and $\mathrm{H}_{2} \mathrm{O}$ are strongly correlated in the southern highlands and that their correlation may indicate that hydrated sulfate compounds are an important reservoir of $\mathrm{H}_{2} \mathrm{O}$ in martian soil (Karunatillake et al., 2014, 2016). The discovery that the $\mathrm{S}-\mathrm{H}_{2} \mathrm{O}$ correlation is paired with a shift in the $\mathrm{S}-\mathrm{Cl}$ correlation advances the limited understanding of the contrast in soil geochemistry across the topographic dichotomy. The change in the $\mathrm{S}-\mathrm{H}_{2} \mathrm{O}$ correlation across the topographic dichotomy (Table 1 and Figure 2; decreased $\mathrm{S}-\mathrm{H}_{2} \mathrm{O}$ correlation in the north) may indicate a decreased abundance or decreased prevalence of hydrated sulfate compounds in lowlands soils. The associated change in $\mathrm{S}-\mathrm{Cl}$ correlation across the dichotomy boundary (increased $\mathrm{S}-\mathrm{Cl}$ correlation in the north) resembles the contrast between excavated and surface soils seen in Gusev crater (Haskin et al., 2005). In Gusev soils, $\mathrm{S}, \mathrm{Cl}$, and $\mathrm{Br}$ correlated strongly in the lightly altered surface soils, but aqueous $\mathrm{H}_{2} \mathrm{O}$ (possibly as brines or thin films) caused these three species to decouple in the older, more altered soils due to their differential solubility (Haskin et al., 2005). Furthermore, previous work at Gusev and Meridiani found that relative trends among $\mathrm{S}$ and $\mathrm{Cl}$ in the shallow subsurface are more consistent with aqueous processes rather than volatilization of $\mathrm{Cl}$ (e.g., via photolysis, Karunatillake et al., 2013). Therefore, the regionally weaker correlation of $\mathrm{S}$ and $\mathrm{Cl}$ seen in the highlands, compared to the lowlands, would be consistent with greater (either longer-lasting or greater intensity) interaction with aqueous $\mathrm{H}_{2} \mathrm{O}$ in the southern highlands, similar to the Gusev soils at the Boroughs and Big Hole sites (Haskin et al., 2005). The relative weakness of S-Cl correlation in the southern highlands provides evidence for aqueous interaction that may lead to alteration and leaching or migration of soluble soil components (e.g., salts containing $\mathrm{S}, \mathrm{Cl}$, or $\mathrm{H}_{2} \mathrm{O}$ ) across much of the highlands. However, long-range transport or concentration of these components is not noted. By contrast, the increased correlation of $\mathrm{S}$ and $\mathrm{Cl}$ in the northern lowlands may indicate less interaction with $\mathrm{H}_{2} \mathrm{O}$ and a lack of alteration at the regional scale. This finding is similar to the unaltered basaltic material observed in Gusev and contrary to previous interpretations (Rogers \& Hamilton, 2015). This lack of alteration may be expected for the Amazonian volcanic units in Amazonis and Elysium Planitia. However, volcanic units only constitute $25 \%$ of the northern lowlands region (Figure 1). The remaining $75 \%$ consists of lowlands and basin units, including mixed transitional units along the dichotomy boundary. Therefore, this signature lacking aqueous interaction is associated not only with young volcanic units but also with the late Hesperian lowlands units found in Utopia, Chryse, and Acidalia Planitia (Tanaka et al., 2014).

Based on the results discussed in section 3.2, it is possible that Ca plays an important role in the geochemical contrast between the lowlands and highlands. Figure 3 shows that the correlation of $\mathrm{Ca}$ and $\mathrm{H}_{2} \mathrm{O}$ is comparable with the $\mathrm{Cl}-\mathrm{H}_{2} \mathrm{O}$ correlation at the regional to global scale. Because Ca-(per)chlorate compounds are likely less common than other compounds (e.g., Mg-perchlorates, Hecht et al., 2009), this correlation may implicate Ca-sulfates as important reservoirs of both $\mathrm{H}_{2} \mathrm{O}$ and $\mathrm{S}$ in martian soil. This result is consistent with remote and in situ observation of Ca-sulfates in various states of hydration (Langevin et al., 2005; Rapin et al., 2016). As a significant reservoir of $\mathrm{S}$ and $\mathrm{H}_{2} \mathrm{O}$, Ca-sulfates would play a role in the geochemical differences between the northern lowlands and southern highlands, and changes in the mineralogy or hydration states of Ca-sulfates could implicate specific aqueous processes in martian soils. However, the trends among Ca, $\mathrm{H}_{2} \mathrm{O}$, and $\mathrm{S}$ between the northern lowlands and southern highlands (Figure 2 and Table 1) do not imply a clear pattern of presence, absence, or change in hydration state among Ca-sulfate species. While evidence is present that Ca-sulfates are an important component of the changes occurring between the lowlands and highlands, these results do not clearly indicate any changes in Ca-sulfate mineralogy or abundance between these two regions that contribute to the proposed history of aqueous interaction. 
Another consideration is the potential influence of surface dust abundance on soil chemistry and, therefore, the trends among the volatile elements. The moderate correlations between volatile elements and DCI in the midlatitudinal analysis (section S2.1) exceed initial expectations and may suggest weak correlation between DCI and soil chemistry. However, the generally weak cumulative correlation between DCI and soil chemistry (excepting Cl, section S2.4) and the lack of strong correlations with DCI in either of the southern highlands or northern lowlands (Figure 2 and Table 1) do not support significant influence of surface dust in the noted shift on correlation among $\mathrm{S}, \mathrm{Cl}$, and $\mathrm{H}_{2} \mathrm{O}$. Relatedly, the atmospheric deposition of salts (Catling et al., 2010) may be an important process in martian soil that could influence $\mathrm{S}$ and $\mathrm{Cl}$ correlation and contribute a substantial portion of soil S and $\mathrm{Cl}$ content (Ewing et al., 2006). However, more research is needed on predicted patterns of atmospheric salt deposition in order to substantiate differential deposition of salts on either side of the dichotomy such that it could cause the distinction between the lowlands and highlands.

Soils in the southern highlands may have interacted with $\mathrm{H}_{2} \mathrm{O}$ via leaching (e.g., hydrothermal vents and fumaroles) or acid fog (i.e., aerosols and low-pH brine films reacting with the soil over geologic time; Hurowitz \& Fischer, 2014; McCollom \& Hynek, 2005) or by more neutral to alkaline processes (Hurowitz et al., 2017). Minerals produced by these processes (e.g., perchlorates and Mg-sulfates) are typically soluble or deliquescent, and the preservation of such phases over geologic time in the near surface necessitates low water-to-rock ratios (e.g., Kounaves et al., 2010). The lack of such evidence of aqueous interaction in the north is not likely due to the lack of aqueous processes occurring in the lowlands, rather aqueous interaction likely preceded the emplacement of the Hesperian-aged units in the lowlands. Relative quiescence of widespread aqueous process and limited soil redistribution since the Hesperian would allow the poorly altered soil at the surface of the northern lowlands to arise from physical weathering of the underlying material with limited chemical weathering. This history is consistent with recent evidence from mineralogical observations (Pan et al., 2017) suggesting that much of the upper $(<2 \mathrm{~km})$ volcanic or volcaniclastic rock in the northern lowlands lacks signatures of significant alteration.

\section{Conclusions}

Based on PCA analysis of GRS chemical maps and DCI data, the interpretation of distinct soil chemistries across the topographic dichotomy is supported. The correlative trends in $\mathrm{S}, \mathrm{Cl}$, and $\mathrm{H}_{2} \mathrm{O}$ abundances are consistent with widespread interaction with aqueous $\mathrm{H}_{2} \mathrm{O}$ in the southern highlands and relatively pristine soils in the northern lowlands. These findings suggest laterally extensive aqueous interaction with bulk soil in southern highlands soils aided by geologically hyper-arid, low-temperature conditions that preserve metastable hydrated minerals over geologic time. The absence of such signatures in the northern lowlands supports a hypothesis of regionally pervasive mantling by minimally weathered soil which postdates widespread aqueous processes in the highlands. The preserved distinctness of soils suggests curtailed mixing between the lowlands and highlands, at least since the emplacement of the Hesperian units in the north. In addition, the distinct correlation of $\mathrm{Ca}$ and $\mathrm{H}_{2} \mathrm{O}$ relative to other rock-forming elements supports the significance of hydrated Ca-compounds as a reservoir of $\mathrm{H}_{2} \mathrm{O}$ in martian soil.

The possible existence of hydrated minerals buried under several kilometers of unaltered material in the northern lowlands (Pan et al., 2017) is consistent with the proposed period of widespread aqueous interaction and alteration that formed both the present southern highlands soil and the possibly buried paleosol in the northern lowlands. In addition, such widespread aqueous processes and soil alteration can create biologically significant redox-sensitive minerals. With the suggestion that organic carbon is found on Mars in low but ubiquitous concentrations (Eigenbrode et al., 2018; Freissinet et al., 2015; Navarro-González et al., 2010), the evidence presented here for aqueous interaction throughout highlands soils may be indicative of a widespread habitable environment in martian soils.

\section{References}

Andrews-Hanna, J. C., Zuber, M. T., \& Banerdt, W. B. (2008). The Borealis basin and the origin of the martian crustal dichotomy. Nature, 453(7199), 1212-1215. https://doi.org/10.1038/nature07011

Boynton, W. V., Taylor, G. J., Evans, L. G., Reedy, R. C., Starr, R., Janes, D. M., et al. (2007). Concentration of H, Si, Cl, K, Fe, and Th in the low- and mid-latitude regions of Mars. Journal of Geophysical Research, 112, E12S99. https://doi.org/10.1029/2007JE002887

Catling, D. C., Claire, M. W., Zahnle, K. J., Quinn, R. C., Clark, B. C., Hecht, M. H., \& Kounaves, S. (2010). Atmospheric origins of perchlorate on mars and in the atacama. Journal of Geophysical Research, 115, E00E11. https://doi.org/10.1029/2009JE003425 
Dehouck, E., Mclennan, S. M., Meslin, P., \& Cousin, A. (2014). Constriants on abundance, composition, and nature of X-ray amorphous components of soils and rocks at Gale Crater, Mars. Journal of Geophysical Research: Planets, 119, 2640-2657. https://doi.org/10.1002/ 2014JE004716

Eigenbrode, J. L., Summons, R. E., Steele, A., Freissinet, C., Millan, M., Navarro-gonzález, R., et al. (2018). Organic matter preserved in 3billion-year-old mudstones at Gale crater, Mars, (June), 1-6. https://doi.org/10.1126/science.aas9185

Ewing, S. A., Sutter, B., Owen, J., Nishiizumi, K., Sharp, W., Cliff, S. S., et al. (2006). A threshold in soil formation at Earth's arid-hyperarid transition. Geochimica et Cosmochimica Acta, 70(21), 5293-5322. https://doi.org/10.1016/j.gca.2006.08.020

Freissinet, C., Glavin, D. P., Mahaffy, P. R., Miller, K. E., Eigenbrode, J. L., Summons, R. E., et al. (2015). Organic molecules in the Sheepbed Mudstone, Gale Crater, Mars. Journal of Geophysical Research: Planets, 120, 495-514. https://doi.org/10.1002/2014JE004737

Frey, H. V., Roark, J. H., Shockey, K. M., Frey, E. L., \& Sakimoto, S. E. H. (2002). Ancient lowlands on Mars. Geophysical Research Letters, 29(10), 1384. https://doi.org/10.1029/2001gl013832

Gasnault, O., Jeffrey Taylor, G., Karunatillake, S., Dohm, J., Newsom, H., Forni, O., et al. (2010). Quantitative geochemical mapping of martian elemental provinces. Icarus, 207(1), 226-247. https://doi.org/10.1016/j.icarus.2009.11.010

Haskin, L. A., Wang, A., Jolliff, B. L., McSween, H. Y., Clark, B. C., Des Marais, D. J., et al. (2005). Water alteration of rocks and soils on Mars at the Spirit rover site in Gusev crater. Nature, 436(7047), 66-69. https://doi.org/10.1038/nature03640

Hecht, M. H., Kounaves, S. P., Quinn, R. C., West, S. J., Young, S. M. M., Ming, D. W., et al. (2009). Detection of perchlorate and the soluble chemistry of martian soil at the Phoenix lander site. Science, 325(5936), 64-67. https://doi.org/10.1126/science.1172466

Hurowitz, J. A., \& Fischer, W. W. (2014). Contrasting styles of water-rock interaction at the Mars Exploration Rover landing sites. Geochimica et Cosmochimica Acta, 127, 25-38. https://doi.org/10.1016/j.gca.2013.11.021

Hurowitz, J. A., Grotzinger, J. P., Fischer, W. W., McLennan, S. M., Milliken, R. E., Stein, N., et al. (2017). Redox stratification of an ancient lake in Gale crater, Mars. Science, 356(6341), eaah6849. https://doi.org/10.1126/science.aah6849

Karunatillake, S., Wray, J. J., Gasnault, O., McLennan, S. M., Deanne Rogers, A., Squyres, S. W., et al. (2016). The association of hydrogen with sulfur on Mars across latitudes, longitudes, and compositional extremes. Journal of Geophysical Research: Planets, 121, 1321-1341. https://doi.org/10.1002/2016JE005016

Karunatillake, S., Wray, J. J., Gasnault, O., McLennan, S. M., Rogers, A. D., Squyres, S. W., et al. (2014). Sulfates hydrating bulk soil in the Martian low and middle latitudes. Geophysical Research Letters, 41, 7987-7996. https://doi.org/10.1002/2014GL061136

Karunatillake, S., Wray, J. J., Squyres, S. W., Taylor, G. J., Gasnault, O., McLennan, S. M., et al. (2009). Chemically striking regions on Mars and Stealth revisited. Journal of Geophysical Research, 114, E12001. https://doi.org/10.1029/2008JE003303

Karunatillake, S., Zhao, Y.-Y. S., McLennan, S. M., Skok, J. R., \& Button, N. E. (2013). Does martian soil release reactive halogens to the atmosphere? Icarus, 226(2), 1438-1446. https://doi.org/10.1016/j.icarus.2013.07.018

Kounaves, S. P., Hecht, M. H., Kapit, J., Gospodinova, K., DeFlores, L., Quinn, R. C., et al. (2010). Wet Chemistry experiments on the 2007 Phoenix Mars Scout Lander mission: Data analysis and results. Journal of Geophysical Research, 115, E00E10. https://doi.org/10.1029/ 2009JE003424

Langevin, Y., Poulet, F., Bibring, J.-P., \& Gondet, B. (2005). Sulfates in the north polar region of Mars detected by OMEGA/Mars Express Science, 307(5715), 1584-1586. https://doi.org/10.1126/science.1109091

Massey, F. J. (1951). The Kolmogorov-Smirnov test for goodness of fit. Journal of the American Statistical Association, 46(253), 68-78.

McCollom, T. M., \& Hynek, B. M. (2005). A volcanic environment for bedrock diagenesis at Meridiani Planum on Mars. Nature, 438(7071), 1129-1131. https://doi.org/10.1038/nature04390

Navarro-González, R., Vargas, E., De La Rosa, J., Raga, A. C., \& McKay, C. P. (2010). Reanalysis of the Viking results suggests perchlorate and organics at midlatitudes on Mars. Journal of Geophysical Research, 115, E12010. https://doi.org/10.1029/2010JE003599

Ojha, L., Lewis, K., Karunatillake, S., \& Schmidt, M. (2018). The Medusae Fossae Formation as the single largest source of dust on Mars. Nature Communications, 9(1), 1, 2867-7. https://doi.org/10.1038/s41467-018-05291-5

Pan, L., Ehlmann, B. L., Carter, J., \& Ernst, C. M. (2017). The stratigraphy and history of Mars' northern lowlands through mineralogy of impact craters: A comprehensive survey. Journal of Geophysical Research: Planets, 122, 1824-1854. https://doi.org/10.1002/ 2017JE005276

Putzig, N., Mellon, M., Kretke, K., \& Arvidson, R. (2005). Global thermal inertia and surface properties of Mars from the MGS mapping mission. Icarus, 173(2), 325-341. https://doi.org/10.1016/j.icarus.2004.08.017

Rapin, W., Meslin, P. Y., Maurice, S., Vaniman, D., Nachon, M., Mangold, N., et al. (2016). Hydration state of calcium sulfates in Gale crater, Mars: Identification of bassanite veins. Earth and Planetary Science Letters, 452, 197-205. https://doi.org/10.1016/j. epsl.2016.07.045

Rogers, A. D., \& Hamilton, V. E. (2015). Compositional provinces of Mars from statistical analyses of TES, GRS, OMEGA and CRISM data. Journal of Geophysical Research: Planets, 120, 62-91. https://doi.org/10.1002/2014JE004690.Received

Ruff, S. W., \& Christensen, P. R. (2002). Bright and dark regions on Mars: Particle size and mineralogical characteristics based on Thermal Emission Spectrometer data. Journal of Geophysical Research, 107(E12), 5127. https://doi.org/10.1029/2001JE001580

Salton, G., \& McGill, M. J. (1983). Introduction to modern information retrieval. New York, NY: McGraw-Hill Book Company.

Tanaka, K. L., et al. (2014). Geologic map of Mars: U.S. Geological Survey Scientific Investigations Map 3292, scale 1:20,000,000. https://doi. $\operatorname{org} / 10.3133 / \operatorname{sim} 3292$

Viviano, C., Murchie, S. L., Daubar, I. J., Morgan, M. F., Seelos, F. P., \& Plescia, J. B. (2019). Composition of Amazonian volcanic materials in Tharsis and Elysium, Mars, from MRO/CRISM reflectance spectra. Icarus, 328, 274-286. https://doi.org/10.1016/j.icarus.2019.03.001

\section{References From the Supporting Information}

Anderson, R., Bridges, J. C., Williams, A., Edgar, L., Ollila, A., Williams, J., et al. (2015). ChemCam results from the Shaler outcrop in Gale crater, Mars. Icarus, 249, 2-21. https://doi.org/10.1016/j.icarus.2014.07.025

Certini, G., \& Ugolini, F. C. (2013). An updated, expanded, universal definition of soil. Geoderma, 192, 378-379. https://doi.org/10.1016/j. geoderma.2012.07.008

Dohm, J. M., Anderson, R. C., Baker, V. R., Ferris, J. C., Hare, T. M., Strom, R. G., et al. (2000). System of gigantic valleys northwest of Tharsis, Mars: Latent catastrophic flooding, northwest watershed, and implications for northern plains ocean. Geophysical Research Letters, 27, 3559-3562. https://doi.org/10.1029/2000GL011728

Feldman, W. C. (2004). Global distribution of near-surface hydrogen on Mars. Journal of Geophysical Research, 109, E09006. https://doi. org/10.1029/2003JE002160 
Haining, R. (2003). Spatial data analysis: Theory and practice. Cambridge: Cambridge University Press.

Hood, D. R., Judice, T., Karunatillake, S., Rogers, D., Dohm, J. M., Susko, D., \& Carnes, L. K. (2016). Assessing the geologic evolution of Greater Thaumasia, Mars. Journal of Geophysical Research: Planets, 121, 1753-1769. https://doi.org/10.1002/2016JE005046

Hunter, J. D. (2007). Matplotlib: A 2D graphic environment. Computing in Science \& Engineering, 9(3), 90-95. https://doi.org/10.1109/ MCSE.2007.55

Hyvärinen, A., \& Oja, E. (2000). Independent component analysis: Algorithms and applications. Neural Networks, 13(4-5), 411-430. https://doi.org/10.1016/S0893-6080(00)00026-5

Jones, E. (2015). Identifying an index of subsurface volatiles on Mars through an anlysis of impact crater morphometry using principal component analysis. Journal of Geophysical Research: Planets, 120, 1023-1043. https://doi.org/10.1002/2014JE004735

Karunatillake, S., Gasnault, O., Squyres, S. W., Keller, J. M., Janes, D. M., Boynton, W. V., \& Newsom, H. E. (2012). Martian case study of multivariate correlation and regression with planetary datasets. Earth, Moon, and Planets, 108(3-4), 253-273. https://doi.org/10.1007/ s11038-012-9395-x

Nowicki, S. a., \& Christensen, P. R. (2007). Rock abundance on Mars from the Thermal Emission Spectrometer. Journal of Geophysical Research, 112, E05007. https://doi.org/10.1029/2006JE002798

Saunders, R. S., Arvidson, R. E., Badhwar, G. D., Boynton, W. V., Christensen, P. R., Cucinotta, F. A., et al. (2004). 2001 Mars Odyssey mission summary. Space Science Reviews, 110(1/2), 1-36. https://doi.org/10.1023/B:SPAC.0000021006.84299.18

Singhal, A. (2001). Modern information retrieval: A brief overview. Bulletin of the IEEE Computer Society Technical Committee on Data Engineering, 1-9.

Świąder, A. (2014). Identification and visualisation of possible ancient ocean shoreline on Mars using submeter-resolution Digital Terrain Models. Geologos, 4, 289-301. https://doi.org/10.2478/logos-2014-0017

Taylor, G. J., Martel, L. M. V., Karunatillake, S., Gasnault, O., \& Boynton, W. V. (2010). Mapping Mars geochemically. Geology, 38(2), 183-186. https://doi.org/10.1130/G30470.1

Rossum, G. van. (1995). Python tutorial, technical report CS-R9526. Amsterdam. 